\title{
Impact of anxiety symptoms on outcomes of depression: an observational study in Asian patients
}

\author{
Diego Novick' \\ William Montgomery ${ }^{2}$ \\ Jaume Aguado 3 \\ Xiaomei Peng ${ }^{4}$ \\ Josep Maria Haro ${ }^{3}$
}

'Eli Lilly and Company, Windlesham, Surrey, UK; ' $E$ Eli Lilly Australia Pty Ltd, West Ryde, NSW, Australia; ${ }^{3}$ Parc Sanitari Sant Joan de Déu, CIBERSAM, Universitat de Barcelona, Barcelona, Spain; ${ }^{4}$ Eli Lilly and Company,

Indianapolis, IN, USA
Correspondence: Diego Novick Eli Lilly and Company, Lilly Research Centre, Erl Wood Manor, Windlesham, Surrey GU20 6PH, UK

Tel +44 I276483832

Fax +44 I276 483 I92

Email novick_diego@lilly.com
This article was published in the following Dove Press journal:

Neuropsychiatric Disease and Treatment

II April 2016

Number of times this article has been viewed

Objective: To investigate the impact of anxiety symptoms on depression outcomes in Asian patients with major depressive disorder (MDD) ( $\mathrm{n}=714)$.

Methods: The 17-item Hamilton Depression Scale (HAMD-17), overall severity, somatic symptoms, and quality of life (QOL) (EuroQOL Questionnaire-5 Dimensions [EQ-5D]) were assessed at baseline and 3 months. Anxiety was measured using items 10 and 11 from the HAMD-17. Linear, tobit, and logistic multiple regression models analyzed the impact of anxiety symptoms on outcomes. Baseline anxiety was related to age and the presence of pain symptoms at baseline.

Results: Regression models showed that a higher level of anxiety was associated with a lower frequency of remission and lower QOL at 3 months. Patients with lower baseline anxiety symptoms had higher remission rates (odds ratio for each point of anxiety symptoms, 0.829 [95\% confidence interval [CI]: 0.723-0.951]). Patients with higher levels of baseline anxiety had a lower QOL at 3 months (a decrease in EQ-5D tariff score for each point of anxiety symptoms, 0.023 [95\% CI: 0.045-0.001]).

Conclusion: In conclusion, the presence of anxiety symptoms negatively impacts the outcomes of depression.

Keywords: depression, anxiety, Asia, observational, outcomes

\section{Introduction}

Anxiety and depressive disorders are highly comorbid. ${ }^{1-4}$ In an analysis of data from the World Health Organization (WHO) World Mental Health surveys (a series of large community epidemiological surveys conducted in ten developed and eight developing countries), for example, all 14 of the 12-month DSM-IV disorders - including anxiety disorders - were significantly and positively associated with 12-month major depressive episodes. ${ }^{2}$ In his review of depression and anxiety, Tiller ${ }^{4}$ concluded that approximately $85 \%$ of patients with depression have significant anxiety and that $90 \%$ of patients with anxiety disorder have depression.

The presence of anxiety symptoms in individuals with major depressive disorder (MDD) has long been proposed as an indicator of poor treatment response and a worse prognosis. ${ }^{5}$ Findings, however, have been mixed; some studies report that response rates in patients with anxious depression were not significantly lower than response rates in those with nonanxious depression, ${ }^{6-8}$ while other studies found treatment to be less effective in patients with anxious depression compared with those with nonanxious depression. ${ }^{9-11}$ More recently, the debate was rekindled by findings from the Sequenced Treatment Alternatives to Relieve Depression (STAR*D) study, in which patients with anxious depression were found to be less likely to respond to 
and achieve remission following antidepressant treatment compared with those with nonanxious depression. ${ }^{5}$ Once again, however, findings from subsequent studies and analyses continue to suggest that anxiety is not a strong predictor of the treatment outcome of depression, ${ }^{12,13}$ and so the debate continues. ${ }^{14}$

Pain further complicates the clinical picture. An association has been reported between pain and depression, as well as between pain and anxiety. ${ }^{15}$ Pain is often found alongside anxiety and depression in primary care patients, ${ }^{16,17}$ and the three phenomena may exhibit different relationships over time. ${ }^{18}$ Pain, like anxiety, has been proposed as a predictor of poor outcomes in depression; depressed patients with pain have been reported to have lower response rates ${ }^{19}$ and lower quality of life (QOL) outcomes ${ }^{20}$ compared with those without pain.

Much of the research into anxious depression, however, has been conducted in European and US populations, and there is little information available from Asian countries. ${ }^{21}$ The objective of this analysis was to assess the influence of anxiety symptoms on outcomes in Asian patients with MDD, taking into account the presence of painful physical symptoms (PPS). We also evaluated the interaction between anxiety symptoms and pain.

\section{Materials and methods Study design and population}

Data for this post hoc analysis were taken from a prospective, noninterventional observational study designed to assess the frequency of somatic symptoms in East Asian patients treated for an acute episode of a MDD in psychiatric care settings. ${ }^{22}$ The study enrolled patients from 30 study sites across six East Asian countries and regions: People's Republic of China, Hong Kong, Korea, Malaysia, Singapore, and Taiwan. Patients were recruited from June 14, 2006 to February 15, 2007, with patients assessed at baseline and at 3 months after treatment.

Patients eligible for inclusion in the study were inpatients or outpatients, at least 18 years of age, who presented with a new or first episode of MDD, as defined by the Diagnostic and Statistical Manual of Mental Disorders, Fourth Edition Text Revision ${ }^{23}$ or International Classification of Diseases, Tenth Revision. ${ }^{24}$ In addition, patients also had to have a Clinical Global Impression-Severity of Illness (CGI-S) ${ }^{25}$ score of $\geq 4$ (moderate) at study entry, at least 2 months free of depression symptoms prior to the onset of the present episode, and consent to participate. Patients were excluded if their current depressive episode had persisted for more than 6 continuous months; if they had a previous or current diagnosis of schizophrenia, schizophreniform disorder, schizoaffective disorder, bipolar disorder, or dementia; were experiencing chronic treatment-resistant pain or pain of an inflammatory origin related to an identified medical condition; or if they were simultaneously participating in another study that included a treatment intervention or an investigational drug.

There were neither restrictions nor recommendations regarding treatment; all treatment decisions were based solely on the clinician's usual practice in the provision of care to patients with MDD. Adverse events were reported to the appropriate authority according to each country's local rules, regulations, and legislation. The study was conducted in accordance with the ethical principles that have their origin in the Declaration of Helsinki and that are consistent with the International Conference on Harmonization good clinical practice guidelines. The study was approved by the institutional or ethical review board of at least one site in each participating country or region. Written informed consent was obtained from all patients or their legal representative prior to enrollment. ${ }^{22}$

\section{Measures}

Demographic and clinical data were collected at the baseline visit. Overall disease severity, and depression and anxiety severity were assessed at baseline and 3 months after treatment. The severity of depression was measured using the 17-item Hamilton Rating Scale for Depression (HAMD-17), ${ }^{26}$ this measure includes anxiety symptoms. Anxiety symptoms were measured separately using items 10 and 11 from the HAMD-17, in which anxiety is rated on a scale from 0 to 8 , with higher anxiety scores indicating increasing severity of anxiety. The modified 15-item Hamilton Rating Scale (HAMD-15) excludes anxiety items 10 and 11 and so assesses the severity of depression without anxiety. Overall disease severity was assessed using the CGI-S.

The presence and absence of PPS (PPS+ and PPS-) was defined as a mean score of $\geq 2$ on the pain-related items of the Somatic Symptom Inventory (SSI). ${ }^{27}$ The SSI is a 28 -item, patient self-report scale that assesses the extent to which each of 28 somatic symptoms bothered the patient over the previous week, using a scale ranging from 1 ("not at all") to 5 ("a great deal"); the pain-related items are abdominal, lower back, joint, neck, heart and chest pain, headache, and muscular soreness.

QOL and health status were assessed using the EuroQOL Questionnaire-5 Dimensions (EQ-5D). ${ }^{28}$ This is a self-rated, 
generic, health-related QOL instrument consisting of two parts; five questions on general health covering the dimensions of mobility, self-care, usual activities, pain/discomfort, and anxiety/depression (EQ-5D); and a visual analog scale (VAS) that patients use to assess their current level of health on the day of scoring from 0 (worst imaginable health state) to 100 (best imaginable health state) (EQ-VAS). The five questions on general health were translated into QOL tariff scores using the available UK population tariffs. ${ }^{29}$

Remission was defined as a HAMD-17 total score of $\leq 7$ at 3 months.

\section{Statistical analysis}

The association between anxiety symptoms at baseline and the outcomes of depression was analyzed using regression models. Multiple linear regression was used for the HAMD-15 and HAMD-17 scores, the CGI, and the EQ-5D VAS. Tobit regression was used for EQ-5D score to account for the ceiling effect at 1 ( $43 \%$ of the sample). Logistic regression was used for remission.

All models were adjusted for age, sex, PPS status, country, the baseline value of the outcome variable, and any other variable associated to the outcome $(P<0.10)$ in the descriptive analysis; the variables that were tested were as follows: previous MDD episodes, hospitalizations, marital status, employment, living arrangements, cardiovascular disease, CGI, HAMD-15, pain intensity, SSI total score, EQ-5D VAS, and tariff. In all models, the interaction term anxiety-PPS was tested.

All statistical analyses were performed using SASC version 9.2 for Windows $^{\mathrm{TM}}$ (SAS Institute, Cary, NC, USA).

\section{Results}

A total of 917 patients were recruited; eight had missing SSI data and so were excluded, leaving 909 patients enrolled in the study. Of these 909 patients, 714 (79\%) had both baseline and 3-month assessments and were included in this analysis. Of the analysis population, $69 \%$ of patients were women, $45 \%$ had previous MDD episodes, and 49\% had PPS (PPS+) at baseline. Mean age at the baseline visit was 45.90 (standard deviation [SD]: 14.18) years, mean CGI-S score was 4.79 (SD: 0.74), and HAMD-17 total score was 23.56 (SD: 5.72).

Analysis of anxiety symptom scores by patient characteristics at baseline is summarized in Table 1. There was a significant difference in anxiety symptoms by PPS status at baseline; patients who were PPS+ had a higher anxiety score than those who were PPS $-(P<0.001)$. There were also
Table I Anxiety symptom score by baseline patient characteristics

\begin{tabular}{|c|c|c|c|}
\hline $\begin{array}{l}\text { Baseline } \\
\text { characteristic }\end{array}$ & $\begin{array}{l}\text { Number } \\
\text { of patients }\end{array}$ & $\begin{array}{l}\text { Anxiety } \\
\text { symptom score, } \\
\text { mean (SD) }\end{array}$ & $P$-value \\
\hline Sex & & & 0.8445 \\
\hline Female & 493 & $3.81(1.46)$ & \\
\hline Male & 221 & $3.83(1.47)$ & \\
\hline Age, years & & & 0.0142 \\
\hline$<40$ & 221 & $3.58(1.49)$ & \\
\hline$\geq 40$ to $<60$ & 373 & $3.90(1.42)$ & \\
\hline$\geq 60$ & 120 & $3.99(1.50)$ & \\
\hline Marital status & & & 0.2706 \\
\hline $\begin{array}{l}\text { Married/de facto } \\
\text { spouse }\end{array}$ & 494 & $3.86(1.49)$ & \\
\hline Single & 108 & $3.61(1.50)$ & \\
\hline $\begin{array}{l}\text { Divorced/widowed/ } \\
\text { separated }\end{array}$ & 112 & $3.81(1.30)$ & \\
\hline \multicolumn{3}{|c|}{ Employment status (part-/full-time work) } & 0.2511 \\
\hline No & 421 & $3.87(1.45)$ & \\
\hline Yes & 291 & $3.74(1.48)$ & \\
\hline Previous MDD episode & & & 0.2897 \\
\hline No & 385 & $3.88(1.47)$ & \\
\hline Yes & 313 & $3.76(1.46)$ & \\
\hline PPS status & & & $<0.001$ \\
\hline PPS- & 361 & $3.48(1.43)$ & \\
\hline PPS+ & 353 & $4.16(1.42)$ & \\
\hline \multicolumn{3}{|l|}{ Number of comorbidities } & 0.3366 \\
\hline None & 534 & $3.78(1.45)$ & \\
\hline I & 130 & $3.98(1.57)$ & \\
\hline$>1$ & 45 & $3.89(1.19)$ & \\
\hline
\end{tabular}

Abbreviations: MDD, major depressive disorder; PPS, painful physical symptoms; $\mathrm{SD}$, standard deviation.

age differences in anxiety ratings, with increasing anxiety ratings with age. There were no significant differences in anxiety symptom scores between any of the other baseline patient characteristic categories (ie, sex, marital status, employment status, previous MDD episodes, and number of comorbidities).

Analysis of anxiety scores at baseline and the severity of depression and QOL at baseline and at 3 months revealed that the correlation between anxiety was significant both at baseline and at 3 months (all $P<0.0001$; Table 2). This finding indicates that anxiety at baseline is related to severity of depression (HAMD-17 and HAMD-15), overall severity (CGI-S), and QOL at baseline, and that anxiety at baseline is also related to the same outcomes at 3 months.

The regression models analyzed the relationship between baseline anxiety and outcome variables, taking into account the presence of other baseline predictors (including HAMD-15, PPS, age, sex, country, hospitalization, marital status, living conditions, work, and comorbidities; Table 3). 
Table 2 Correlation between anxiety score at baseline and severity of depression and QOL at baseline and at 3 months

\begin{tabular}{lll}
\hline Parameter & Pearson correlation & P-value \\
\hline Baseline & & \\
CGI-S score & 0.326 & $<0.000$ I \\
HAMD-I7 total score & 0.659 & $<0.000$ I \\
HAMD-I5 total score & 0.473 & $<0.000$ I \\
EQ-5D tariff score & -0.334 & $<0.000$ I \\
EQ-5D VAS score & -0.197 & $<0.000$ I \\
3 months & & \\
CGI-S score & 0.142 & 0.000 I \\
HAMD- I7 total score & 0.20 & $<0.000$ I \\
HAMD-I5 total score & 0.162 & $<0.000$ I \\
EQ-5D tariff score & -0.16 & $<0.000$ I \\
EQ-5D VAS score & -0.123 & $0.00 \mathrm{I}$ \\
\hline
\end{tabular}

Note: ${ }^{2 H A M D}-15$ includes all but anxiety symptoms of HAMD- 17.

Abbreviations: CGI-S, Clinical Global Impression-Severity; EQ-5D, EuroQOL Questionnaire-5 Dimensions; HAMD, Hamilton Depression Rating scale; QOL, quality of life; VAS, visual analog scale.

Patients with higher levels of baseline anxiety symptoms had lower remission rates (odds ratio [OR] of remission for each point of anxiety symptoms, 0.829 [95\% CI: 0.723-0.951]). Patients with higher levels of baseline anxiety symptoms had a lower level of QOL at 3 months (decrease in EQ-5D VAS score for each point of anxiety symptoms, 0.955 [95\% CI: 0.093-2.003]). In the models analyzing the impact of anxiety symptoms overall severity (CGI-S), HAMD-15 and EQ-5D scores showed that the presence of anxiety was associated with worse outcomes, but this association did not reach statistical significance when adjusting for other covariates. In all of the models, pain (PPS+ status) was highly predictive of poor outcomes. The interaction of anxiety and PPS+ was not significant in any of the models.

\section{Discussion}

The main findings of this study were that anxiety symptoms in Asian MDD patients are associated with worse remission

Table 3 Effect of anxiety on outcomes at 3 months (linear and logistic regression models)

\begin{tabular}{lll}
\hline Outcomes & $\begin{array}{l}\text { Effect of anxiety } \\
\text { symptoms }\end{array}$ & $\mathbf{9 5 \%} \mathbf{~ C l}$ \\
\hline CGI-S score & 0.049 & -0.010 to 0.109 \\
HAMD-I5 total score & 0.194 & -0.085 to 0.474 \\
EQ-5D VAS score & -0.955 & -2.003 to 0.093 \\
EQ-5D tariff score & -0.023 & -0.045 to -0.00 I \\
& Anxiety OR & $\mathbf{9 5 \%} \mathbf{C l}$ \\
Remission & 0.829 & 0.723 to 0.95 I \\
\hline
\end{tabular}

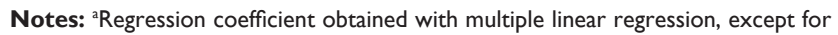
the EQ-5D tariff where tobit regression was used. 'OR from logistic regression.

Abbreviations: CGI-S, Clinical Global Impression-Severity; EQ-5D, EuroQOL Questionnaire-5 Dimensions; HAMD, Hamilton Depression Rating scale; VAS, visual analog scale; $\mathrm{OR}$, odds ratio; $\mathrm{QOL}$, quality of life; $\mathrm{Cl}$, confidence interval. and QOL (EQ-5D tariff score) at 3 months. These findings were maintained in the regression model when adjusting for other covariates. The relationship between anxiety, depression, and QOL outcomes was strong in the descriptive analysis, but was weaker when adjusted for the presence of other covariates, particularly pain status. Our findings also indicate that pain is a significant predictor of poor outcome and that anxiety and pain are related.

As findings in the literature are mixed, the findings of this analysis conflict with some studies and agree with others. Specifically, the findings of our analysis conflict with the large amount of data from placebo-controlled clinical trials of antidepressants, and a number of analyses that suggest that anxiety is not a strong predictor of the treatment outcome of depression, that response rates in patients with anxious depression were not significantly lower than response rates in those with nonanxious depression, and that drug-placebo differences did not differ between the two groups. ${ }^{6-8,12-14}$ In contrast, our findings are in line with a modest amount of data from a smaller number of open-label and naturalistic studies that reported the presence of anxiety symptoms in individuals with MDD to be an indicator of poor treatment response and a worse prognosis., , $^{-11}$

There is currently no universally accepted definition of anxious depression; ${ }^{14}$ the WHO is revising the primary health care classification of mental and behavioral disorders to accommodate this condition. ${ }^{30}$ It is possible that different results relating to anxious depression outcomes are being reported by different studies because they are assessing subtly different patient populations, and using different measures to assess anxiety symptoms within these populations. This study focused on MDD patients with anxiety symptoms and used a modified version of the HAMD-17 to do this. In the STAR*D study, anxious depression was defined as MDD with high levels of anxiety symptoms based on a different modification of the HAMD-17 scale. ${ }^{5}$ The Clinical Research Center for Depression (CRESCEND) study specifically excluded comorbid anxiety disorder from their anxious depression population, and used a Hamilton Anxiety Scale total score of $\geq 20$ to define anxious depression. ${ }^{14,31}$ Further work is required to optimize the identification of anxious depression as a clinically significant subtype of depression, and as an aid to tailoring treatment for individual MDD patients. ${ }^{14}$

Differing effects among antidepressant drugs have been reported, ${ }^{32}$ and it is possible that the selection of antidepressants with anxiolytic effects may lead to improved depression outcomes in patients with anxious depression. Studies that have not found anxiety symptoms to predict poorer depression outcomes may have used different antidepressants with 
anxiolytic effects. ${ }^{14}$ It has also been suggested that the use of fixed treatment modalities, as occurred in the STAR*D study $^{5}$ rather than a broader treatment (flexible treatment plus the allowance of concomitant medications including anxiolytics/hypnotics and antipsychotics) as used in the CRESCEND study ${ }^{14}$ might account for different findings between studies. This analysis did not take into account the antidepressant prescribed, or the treatment modality (broad and flexible versus fixed), which might have influenced outcomes.

The findings from this study indicate that anxiety and pain are related. This finding is in line with those from the study conducted by Means-Christensen et $\mathrm{a}^{15}$ in which an association was reported not only between pain and depression, but also between pain and anxiety; patients with an anxiety or depressive disorder reported greater interference from pain, while patients with pain symptoms reported lower mental health functioning and more severe depression and anxiety disorders. Anxiety, depression, and pain appear to share similar pathophysiological mechanisms, ${ }^{33,34}$ and a neurochemical pathway that is influenced by serotonin. ${ }^{35,36}$ However, the association between these phenomena is complex, underlying mechanisms are not yet fully understood, and the specific interrelationships remain unclear.

While the relationships between anxiety symptoms and pain in MDD remain obscure, the clinical implications of these findings seem clear - that clinicians need to take into account the presence of both anxiety and pain when treating patients with depression.

\section{Limitations}

Some limitations should be considered when interpreting the results of this analysis. Given the observational design of the study from which the data are drawn, our findings should be interpreted conservatively. The presence of anxiety symptoms in our MDD patients was assessed using two items of the HAMD and not with a specific scale. Only patients from psychiatric care settings and no patients from primary care were included, which means that our patient sample is not representative of the whole MDD population in these Asian countries and thus limits the generalizability of our findings to primary care patients with MDD. As mentioned previously, this analysis did not take into account the antidepressant prescribed, which may influence outcomes at 3 months. Furthermore, the use of pain relief medication was not assessed. Finally, as there is no Asian EQ-5D tariff, we applied the commonly used UK tariff to the EQ-5D data of the Asian patients to calculate the utility scores. ${ }^{28}$ While there is evidence that different populations (including different racial/ethnic populations) value health states differently, ${ }^{37-39}$ the EQ-5D has been shown to be useful for assessing QOL in patients with $\mathrm{MDD}^{40}$ and to have acceptable validity and reliability in Asian populations. ${ }^{41}$ In addition, both the EQ-VAS and the EQ-5D utility scores have been shown to be responsive to change in patients with depression. ${ }^{42}$

\section{Conclusion}

The presence of anxiety symptoms in Asian MDD patients negatively impacts remission status and QOL, indicating that anxiety symptoms should be taken into account when tailoring therapy for individual patents. It is important to note that pain and anxiety symptoms are also related. Further studies are needed to understand the relationships between pain and anxiety symptoms in MDD patients.

\section{Author contributions}

$\mathrm{DN}, \mathrm{WM}, \mathrm{JMH}$, and XMP were involved in the conception and design of the work, acquisition of the data, and interpretation of the data. JA conducted the analysis and was involved in interpretation of the data. All authors have been involved in drafting the article, providing critical revision of the intellectual content, and approving the final version. All authors have agreed to be accountable for all aspects of the work.

\section{Disclosure}

This study has been funded by Eli Lilly and Company. Diego Novick, William Montgomery, and Xiaomei Peng are Eli Lilly and Company employees. Josep Maria Haro has participated in advisory boards or given educational presentations for Eli Lilly and Company, Roche, Lundbeck, and Otsuka. Jaume Aguado has performed the statistical analyses under a contract of Fundació Sant Joan de Déu with Eli Lilly and Company. The authors report no other conflicts of interest in this work.

\section{References}

1. Johansson R, Carlbring P, Heedman Å, Paxling B, Andersson G. Depression, anxiety and their comorbidity in the Swedish general population: point prevalence and the effect on health-related quality of life. Peer J. 2013;1:e98.

2. Kessler RC, Birnbaum HG, Shahly V, et al. Age differences in the prevalence and co-morbidity of DSM-IV major depressive episodes: results from the WHO World Mental Health Survey Initiative. Depress Anxiety. 2010;27(4):351-364.

3. Rapaport MH. Prevalence, recognition and treatment of comorbid depression and anxiety. J Clin Psychiatry. 2001;62(Suppl 24):6-10.

4. Tiller JWG. Depression and anxiety. Med J Aust Open. 2012;(1 Suppl 4): 28-32.

5. Fava M, Rush AJ, Alpert JE, et al. Difference in treatment outcome in outpatients with anxious versus nonanxious depression: a STAR*D report. Am J Psychiatry. 2008;165(3):342-351.

6. Nelson JC. Anxiety does not predict response to duloxetine in major depression: results of a pooled analysis of individual patient data from 11 placebo-controlled trials. Depress Anxiety. 2010;27(1):12-18. 
7. Nelson JC, Delucchi K, Schneider LS. Anxiety does not predict response to antidepressant treatment in late life depression: results of a metaanalysis. Int J Geriatr Psychiatry. 2009;24(5):539-544.

8. Russell JM, Koran LM, Rush J, et al. Effect of concurrent anxiety on response to sertraline and imipramine in patients with chronic depression. Depress Anxiety. 2004;13(1):18-27.

9. Altamura AC, Montresor C, Salvadori D, Mundo E. Does comorbid subthreshold anxiety affect clinical presentation and treatment response in depression? A preliminary 12-month naturalistic study. Int J Neuropsychopharmacol. 2004;7(4):481-487.

10. Clayton PJ, Grove WM, Coryell W, et al. Follow-up and family study of anxious depression. Am J Psychiatry. 1991;148(11):1512-1517.

11. Gaynes BN, Magruder KM, Burns BJ, et al. Does a coexisting anxiety disorder predict persistence of depressive illness in primary care patients with major depression? Gen Hosp Psychiatry. 1999;21(3):158-167.

12. Thase ME, Demyttenaere K, Earley WR, et al. Extended release quetiapine fumarate in major depressive disorder: analysis in patients with anxious depression. Depress Anxiety. 2012;29(7):574-586.

13. Uher R, Dernovsek MZ, Mors O, et al. Melancholic, atypical and anxious depression subtypes and outcome of treatment with escitalopram and nortriptyline. J Affect Disord. 2011;132(1-2):112-120.

14. Seo HJ, Song HR, Jeong S, et al. Does comorbid subthreshold anxiety predict treatment response in depression? Results from a naturalistic cohort study (the CRESCEND study). J Affect Disord. 2014;152-154: 352-359.

15. Means-Christensen AJ, Roy-Byrne PP, Sherbourne CD, Craske MG, Stein MB. Relationships among pain, anxiety, and depression in primary care. Depress Anxiety. 2008;25(7):593-600.

16. Gureje O, Simon GE, Von Korff M. A cross-national study of the course of persistent pain in primary care. Pain. 2001;92(1-2):195-200.

17. Mergl R, Seidscheck I, Allgaier AK, et al. Depressive, anxiety, and somatoform disorders in primary care: prevalence and recognition. Depress Anxiety. 2007;24(3):185-195.

18. Castillo RC, Wegener ST, Heins SE; for the LEAP Study Group. Longitudinal relationships between anxiety, depression, and pain: results from a two-year cohort study of lower extremity trauma patients. Pain. 2013;154(12):2860-2866.

19. Novick D, Montgomery W, Aguado J, et al. Which somatic symptoms are associated with an unfavorable course in Asian patients with major depressive disorder? J Affect Disord. 2013;149(1-3):182-188.

20. Novick D, Montgomery W, Kadziola Z, et al. Do concomitant pain symptoms in patients with major depression affect quality of life even when taking into account baseline depression severity? Patient Prefer Adherence. 2013;7:463-470.

21. Li Y, Shi S, Yang F, et al. Patterns of co-morbidity with anxiety disorders in Chinese women with recurrent major depression. Psychol Med. 2012; 42(6): 1239-1248.

22. Lee $\mathrm{P}$, Zhang $\mathrm{M}$, Hong JP, et al. Frequency of painful physical symptoms with major depressive disorder in Asia: relationship with disease severity and quality of life. J Clin Psychiatry. 2009;70(1):83-91.

23. American Psychiatric Association (APA). Diagnostic and Statistical Manual of Mental Disorders Text Revision: DSM-IV-TR. Washington, DC: American Psychiatric Press; 2000.

24. World Health Organization (WHO). International Classification of Diseases and Related World Health Problems. Geneva, Switzerland: WHO; 2007.
25. Guy W. ECDEU Assessment Manual for Psychopharmacology, Revised. Bethesda, MD: US Department of Health, Education, and Welfare; 1976.

26. Hamilton M. A rating scale for depression. J Neurol Neurosurg Psychiatry. 1960;23:56-62.

27. Kroenke K, Spitzer RL, Williams JB, et al. Physical symptoms in primary care. Predictors of psychiatric disorders and functional impairment. Arch Fam Med. 1994;3(9):774-779.

28. Brooks R, Rabin R, de Charro F. The Measurement and Valuation of Health Status Using EQ-5D: A European Perspective. Dordrecht, The Netherlands: Kluwer Academic Publishers; 2003.

29. Kind P, Hardman G, Macran S. UK population norms for EQ-5D. Working Paper \#172. York, UK: York Centre for Health Economics; 1999.

30. Lam TP, Goldberg DP, Dowell AC, et al. Proposed new diagnoses of anxious depression and bodily stress syndrome in ICD-11-PHC: an international focus group study. Fam Pract. 2013;30(1):76-87.

31. Hamilton M. The assessment of anxiety states by rating. $\mathrm{Br} J \mathrm{Med}$ Psychol. 1959;32:50-55.

32. Cipriani A, Furukawa TA, Salanti G, et al. Comparative efficacy and acceptability of 12 new-generation antidepressants: a multipletreatments meta-analysis. Lancet. 2009;373(9665):746-758.

33. Basbaum AI, Fields HL. Endogenous pain control mechanisms: review and hypothesis. Ann Neurol. 1978;4(5):451-462.

34. Rex A, Fink H. Neurotransmitter and behaviour: serotonin and anxiety. In: Uehara T, editor. Psychiatric Disorders - Trends and Developments. 2001. InTech. Available from: http://www.intechopen.com/books/ psychiatric-disorders-trends-and-developments/neurotransmitter-andbehaviour-serotonin-and-anxiety. Accessed July 28, 2014.

35. Kapfhammer H-P. Somatic symptoms in depression. Dialogues Clin Neurosci. 2006;8(2):227-239.

36. Griebel G. 5-Hydroxytryptamine-interacting drugs in animal models of anxiety disorders: more than 30 years of research. Pharmacol Ther. 1995;65(3):319-395.

37. Johnson JA, Luo N, Shaw JW, Kind P, Coons SJ. Valuations of EQ-5D health states: are the United States and United Kingdom different? Med Care. 2005;43(3):221-228.

38. Fu AZ, Kattan MW. Racial and ethnic differences in preference-based health status measure. Curr Med Res Opin. 2006;22(12):2439-2448.

39. Norman R, Cronin P, Viney R, et al. International comparisons in valuing EQ-5D health states: a review and analysis. Value Health. 2009; 12(8):1194-1200

40. Sapin C, Fantino B, Nowicki ML, Kind P. Usefulness of EQ-5D in assessing health status in primary care patients with major depressive disorder. Health Qual Life Outcomes. 2004;2:20.

41. Wang HM, Patrick DL, Edwards TC, et al. Validation of the EQ-5D in a general population sample in urban China. Qual Life Res. 2012;21(1): $155-160$.

42. Gerhards SA, Huibers MJ, Theunissen KA, et al. The responsiveness of quality of life utilities to change in depression: a comparison of instruments (SF-6D, EQ-5D, and DFD). Value Health. 2011;14(5): 732-739.
Neuropsychiatric Disease and Treatment

\section{Publish your work in this journal}

Neuropsychiatric Disease and Treatment is an international, peerreviewed journal of clinical therapeutics and pharmacology focusing on concise rapid reporting of clinical or pre-clinical studies on a range of neuropsychiatric and neurological disorders. This journal is indexed on PubMed Central, the 'PsycINFO' database and CAS,

\section{Dovepress}

and is the official journal of The International Neuropsychiatric Association (INA). The manuscript management system is completely online and includes a very quick and fair peer-review system, which is all easy to use. Visit http://www.dovepress.com/testimonials.php to read real quotes from published authors. 